\title{
Apixaban for Stroke Prevention in Atrial Fibrillation: Why are Event Rates Higher in Clinical Practice than in Randomized Trials?-A Systematic Review
}

\author{
Tim A. C. de Vries ${ }^{1,2,30}$ Jack Hirsh ${ }^{4,5}$ Ke Xu ${ }^{1,6}$ Imaad Mallick ${ }^{1}$ Vinai C. Bhagirath ${ }^{4,5}$ \\ John W. Eikelboom ${ }^{1,4,5}$ Jeffrey S. Ginsberg ${ }^{4,5}$ Paul C. Kruger ${ }^{1,7}$ Noel C. Chan ${ }^{1,4,5}$
}

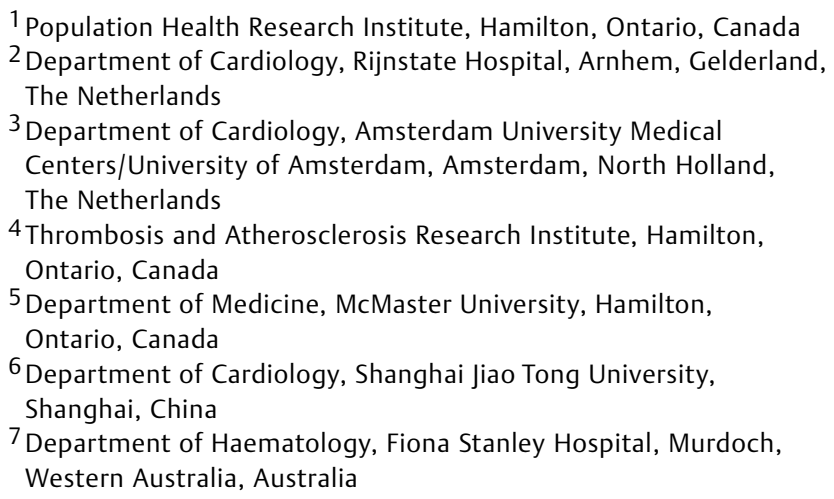

Address for correspondence Noel C. Chan, MBBS, Thrombosis and Atherosclerosis Research Institute, DBCVRI, McMaster University, 237 Barton St East, Hamilton, ON L8S 4L8, Canada (e-mail: noel. chan@taari.ca).

\begin{abstract}
Keywords

- anticoagulants

- death

- hemorrhage

- off-label

- thromboembolism

Background Recent reports suggest an important contribution from frequent offlabel use of apixaban $2.5 \mathrm{mg}$ twice daily to the higher rates of thromboembolic events observed in observational studies (OSs) relative to in randomized controlled trials (RCTs), and consequently, advocate against such use in all patients.

Objectives To examine factors contributing to the higher thromboembolic event rates, we estimated the prevalence of off-label use in contemporary practice, and compared patient characteristics and rates of stroke/systemic embolism, major bleeding, and mortality by apixaban dose and by study design in a systematic review and meta-analysis.

Results and Discussion We identified 18 OSs and 2 RCTs that included 155,228 and 11,928 patients, respectively. Patients in OSs more often received apixaban $2.5 \mathrm{mg}$ twice daily (31.3\% vs. $5.1 \%$ ), were older (mean age 73.8 vs. 69.8 years), and had higher $\mathrm{CHA}_{2} \mathrm{DS}_{2}$-VASc scores (mean 3.6 vs. 2.9) versus those in RCTs. We observed a consistent pattern of higher rates of thromboembolic events, bleeding, and mortality in patients treated with 2.5 versus $5 \mathrm{mg}$ twice daily apixaban in both OSs and RCTs.

Conclusion The higher risk profiles of patients in OSs versus RCTs, and higher rates of both bleeding and mortality not attributable to thromboembolism in patients treated with apixaban 2.5 versus $5 \mathrm{mg}$ twice daily suggest that differences in patient characteristics are additional important contributors to the higher than expected thromboembolic event rates in clinical practice.
\end{abstract}

received

September 9, 2019

accepted after revision

May 17, 2020
(C) 2020 Georg Thieme Verlag KG Stuttgart · New York
DOI https://doi.org/ $10.1055 / \mathrm{s}-0040-1713889$. ISSN 0340-6245. 


\section{Introduction}

Apixaban, a direct acting oral anticoagulant, has been evaluated for stroke prevention in atrial fibrillation (AF) in two phase III trials: AVERROES (apixaban vs. aspirin) and ARISTOTLE (apixaban vs. warfarin). In both trials, apixaban was dosed according to an explicit dosing strategy, which was informed by results of pre-phase III studies. The standard dose of $5 \mathrm{mg}$ twice daily was given to most patients and a reduced dose of $2.5 \mathrm{mg}$ twice daily to those who met at least two of three clinical characteristics (age $\geq 80$ years, body weight $\leq 60 \mathrm{~kg}$, and creatinine level $\geq 133 \mu \mathrm{mol} / \mathrm{L}$ ), known as the $\mathrm{ABC}$ criteria which are independently associated with increased apixaban levels. In AVERROES, apixaban proved to be more effective than aspirin in preventing the composite of stroke and systemic embolism events (S/SEE) and did not result in more major bleeding, whereas in ARISTOTLE, it was shown to be both more effective and safer than warfarin. ${ }^{1,2}$

Now, several years after the approval of apixaban by regulatory authorities, several large health databases and registries report rates of thromboembolic events and bleeding with apixaban that are higher than those observed in the earlier phase III randomized controlled trials (RCTs), ${ }^{1-21}$ particularly in those treated with the 2.5-mg dose. $6,7,11,16,18,21$ These observations are in keeping with the generally accepted view that, because of different criteria used for patient selection, rates of adverse events are higher in observational studies than in RCTs. ${ }^{22}$

On the other hand, recent data provide another potentially treatable cause for the higher rates of thromboembolic events in patients prescribed apixaban in clinical practice. Thus, several observational studies have reported that the 2.5-mg dose of apixaban is used much more frequently in clinical practice than in RCTs, $1,2,7,9,10,12,13,15,16,19,20$ that approximately $50 \%$ of patients who receive this dose do not meet two or more of the $A B C$ criteria (i.e., off-label use), ${ }^{23-31}$ and that such use is associated with an increased risk of thromboembolic events. ${ }^{23,29,32-34}$ On these grounds, several authors and guidance documents advocate against the off-label use of the 2.5-mg dose in all patients. ${ }^{23,29,32-36}$

Based on the above considerations, we sought to determine the factors contributing to the higher thromboembolic event rates. To achieve this aim, we estimated the prevalence of off-label use in contemporary practice, and compared baseline characteristics and rates of thromboembolic events, bleeding, and death in patients with AF by dose of apixaban (2.5 vs. $5 \mathrm{mg}$ twice daily) and by study design (observational studies vs. RCTs).

\section{Methods}

We performed a systematic search for RCTs and observational studies reporting on clinical outcomes in AF patients taking apixaban for the prevention of ischemic stroke using the Ovid MEDLINE and the PubMed Central databases from the inception of these databases up to and including October 2019. The search strategy included the following keywords: "apixaban"
AND "atrial fibrillation" AND "thromboembolism" OR "embolism" OR "stroke" OR "haemorrhage" OR "hemorrhage" OR "bleeding” OR "mortality" OR “death.” English publications that reported on absolute annualized rates of thromboembolic events, bleeding, and/or death in patients with AF taking apixaban were eligible for inclusion. The search was supplemented by screening the reference lists of recent systematic reviews on similar topics identified from the initial search. We excluded studies enrolling less than 1,000 patients to minimize small-study effect. After deduplication, all hits were screened for eligibility in duplication. In the instance of disagreement, the final decision was determined by a third reviewer.

Assessing the quality of evidence of meta-analyses of observational studies reporting on event rates is less well established than for those of RCTs reporting on the treatment effect of interventions. ${ }^{37}$ Through iterative discussion, we developed an instrument to categorize studies according to their risk of bias and adopted the Grading of Recommendations Assessment, Development and Evaluation system. ${ }^{38}$ Accordingly, we rated the quality of evidence for each clinical outcome (-Supplementary Material S1, available in the online version). All quality assessments were performed by two reviewers and any disagreement resolved by consensus with a third.

Articles reporting on the same database were included but we avoided double counting by using data of interest from the more comprehensive publication (-Supplementary Material S1: - Tables 1 and 2, and - Supplementary Material S2 and S3, available in the online version). For each study, we extracted data for baseline characteristics (e.g., age and $\mathrm{CHA}_{2} \mathrm{DS}_{2}$-VASc score), dosing practice (i.e., the proportion of patients receiving the 2.5 - or $5-\mathrm{mg}$ dose), and clinical adverse outcomes (i.e., S/SEE, ischemic stroke, major bleeding, intracranial hemorrhage [ICH], and all-cause death). All extractions were performed by the primary author, and any errors corrected by a secondary author by reviewing the original publications. We presented the data for baseline characteristics and dosing practice as weighted pooled estimates for means (according to study size) and standard deviations (SDs), ${ }^{39}$ or as proportions. ${ }^{40-42}$ In the instance that means were not reported in the original study, we used the reported medians and (interquartile) ranges to estimate means and SDs (-Supplementary Material S2, available in the online version $).{ }^{43}$

By taking time of follow-up of each study into consideration, we estimated the annual number of events for each clinical outcome prior to pooling (- Supplementary Material S2, available in the online version). To calculate a pooled estimate for each outcome, we used the Freeman-Tukey transformation under a fixed effect model, or a random effects model if significant inconsistency was observed (-Supplementary Material S1: - Tables 6 and 8 , available in the online version). ${ }^{40-42}$

To compare clinical outcomes between RCTs and descriptive studies, we reported a relative risk (RR) and a 95\% confidence interval $(\mathrm{CI})$ for apixaban-treated patients, irrespective of dose, and for patients treated with either 2.5 or 
5 mg. ${ }^{44-46}$ We performed separate analyses for bleeding events and for patients treated with a vitamin $\mathrm{K}$ antagonist (VKA) to assess for consistency in our findings.

\section{Results}

Our original search yielded 3,186 publications, and an additional 61 by screening reference lists. Of these, 1,593 were unique publications, most of which $(n=1,504 ; 94.4 \%)$ were excluded after screening titles and/or abstracts. Another 69 were excluded due to various reasons after full paper assessment, including presence of duplicate datasets. Overall, we included 18 observational studies and 2 RCTs (AVERROES and ARISTOTLE) in our analyses

Table 1 Characteristics of patients on apixaban or vitamin $\mathrm{K}$ antagonists in observational studies and in randomized controlled trials

\begin{tabular}{|c|c|c|}
\hline Characteristics & $\begin{array}{l}\text { Observational } \\
\text { studies }\end{array}$ & $\begin{array}{l}\text { Randomized } \\
\text { controlled trials }\end{array}$ \\
\hline \multicolumn{3}{|c|}{ Apixaban, either dose } \\
\hline No. of patients & 155,228 & 11,928 \\
\hline $2.5 \mathrm{mg}$ users & $31.3 \%$ & $5.1 \%$ \\
\hline Age - y & $73.8 \pm 11.1$ & $69.8 \pm 9.5$ \\
\hline Females & $50.3 \%$ & $36.7 \%$ \\
\hline $\mathrm{CHA}_{2} \mathrm{DS}_{2}$-VASC & $3.6 \pm 1.7$ & $2.9 \pm 1.7^{a}$ \\
\hline \multicolumn{3}{|l|}{$\begin{array}{l}\text { Apixaban, } 5 \mathrm{mg} \\
\text { twice daily }\end{array}$} \\
\hline No. of patients & 67,296 & 10,939 \\
\hline Age - y & $70.5 \pm 10.4$ & $68.6 \pm 9.6^{b}$ \\
\hline Females & $40.2 \%$ & $38.9 \%^{\mathrm{b}}$ \\
\hline $\mathrm{CHA}_{2} \mathrm{DS}_{2}$-VASc & $3.2 \pm 1.7$ & - \\
\hline \multicolumn{3}{|l|}{$\begin{array}{l}\text { Apixaban, } 2.5 \mathrm{mg} \\
\text { twice daily }\end{array}$} \\
\hline No. of patients & 25,377 & 596 \\
\hline Age $-y$ & $83.1 \pm 7.9$ & $83.6 \pm 3.7^{b}$ \\
\hline Females & $60.3 \%$ & $65.5 \%{ }^{b}$ \\
\hline $\mathrm{CHA}_{2} \mathrm{DS}_{2}$-VASC & $4.7 \pm 1.5$ & - \\
\hline \multicolumn{3}{|l|}{$\begin{array}{l}\text { Vitamin } \mathrm{K} \\
\text { antagonists }\end{array}$} \\
\hline No. of patients & 385,013 & 9,081 \\
\hline Age - y & $76.8 \pm 11.1$ & $69.7 \pm 9.6$ \\
\hline Females & $44.6 \%$ & $35.0 \%$ \\
\hline $\mathrm{CHA}_{2} \mathrm{DS}_{2}$-VASC & $3.7 \pm 1.7$ & $2.9 \pm 1.7^{a}$ \\
\hline
\end{tabular}

Abbreviations: $\mathrm{CHA}_{2} \mathrm{DS}_{2}-\mathrm{VASC}$ (a score that estimates the annual risk of stroke for patients with atrial fibrillation), Congestive heart failure, Hypertension, Age $\geq 75$ years ( 2 points), Diabetes mellitus, Prior Stroke or TIA or thromboembolism (2 points), Vascular disease, Age between 65-74 years, Sex category; SD, standard deviation.

Note: Values represent the absolute numbers, percentages, or means \pm standard deviations.

${ }^{a}$ Derived from a substudy of the ARISTOTLE trial. ${ }^{47}$

${ }^{b}$ Derived from a substudy of the AVERROES trial. ${ }^{48}$
(-Supplementary Material S1: -Fig. 1 and -Table 2, available in the online version). ${ }^{1-20}$

- Table 1 describes the clinical characteristics of the patients who were treated with either apixaban or a VKA in the two types of studies. Patients treated with apixaban in observational studies were older (mean age 73.8 vs. 69.8 years), had higher $\mathrm{CHA}_{2} \mathrm{DS}_{2}$-VASc scores (mean 3.6 vs. 2.9), and were far more likely to receive the reduced dose (31.3\% vs. $5.1 \%$ ), than those enrolled in RCTs. ${ }^{1-4,7,9,10,12,13,15-17,19,20,47}$ Apixaban-treated patients prescribed $5 \mathrm{mg}$ were older in observational studies than in RCTs (mean age 70.5 vs. 68.6 years), ${ }^{7,9,11,14,16,21,48}$ whereas for those on $2.5 \mathrm{mg}$ no important difference was observed (mean age 83.1 vs. 83.6 years). ${ }^{7,9,11,16,18,21,48}$ We were unable to find data on $\mathrm{CHA}_{2} \mathrm{DS}_{2}$-VASc scores per dosing regimen of apixaban for patients enrolled in the RCTs. Similarly, compared with patients treated with a VKA in RCTs, VKA-treated patients included in observational studies were older (mean age 76.8 vs. 69.7 years), and had higher $\mathrm{CHA}_{2} \mathrm{DS}_{2}$-VASc scores (mean 3.7 vs. 2.9). ${ }^{2-4,7-9,15,16,18-20}$

- Table 2 shows the rates of S/SEE, ischemic stroke, major bleeding, ICH, and mortality of patients treated with either apixaban or a VKA in observational studies, compared with those in RCTs. Patients treated with apixaban in observational studies had higher rates of S/SEE (RR 1.62; 95\% CI 1.19-1.64), major bleeding (RR 1.37; 95\% CI 1.20-1.56), ICH (RR 1.61; 95\% CI 1.17-2.20), and mortality (RR 1.91; 95\% CI 1.73-2.11) than those treated with apixaban in RCTs. ${ }^{1-10,12,13,15-17,19,20}$ Patients treated with apixaban $5 \mathrm{mg}$ twice daily in observational studies had higher rates of S/SEE (RR 1.40; 95\% CI 1.14-1.73), major bleeding (RR $1.34 ; 95 \%$ CI 1.15-1.56), and mortality (RR 1.16; 95\% CI 1.00-1.35) than those in RCTs. ${ }^{6,7,11,14,16,21}$ A similar trend was observed for those treated with apixaban $2.5 \mathrm{mg}$ twice daily: rates of S/SEE (RR 2.10; 95\% CI 0.95-4.67), major bleeding (RR 1.18; 95\% CI 0.70-1.99), and mortality (RR 1.19; 95\% CI 0.89-1.58) were higher compared with patients on the same dose in RCTs, but the difference did not reach statistical significance. ${ }^{6,7,11,16,18,21}$ We were unable to obtain rates of ICH by dose of apixaban for patients enrolled in RCTs. Users of VKAs in observational studies also had higher rates of S/SEE (RR 1.55; 95\% CI 1.32-1.82), major bleeding (RR $1.39 ; 95 \% \mathrm{CI} 1.24-1.56$ ), and mortality (RR 1.51; 95\% CI 1.36-1.67) than those enrolled in RCTs, but rates of ICH were similar (RR 1.08; 95\% CI 0.86-1.36). ${ }^{2-9,12,15,16,18,20}$

- Table 3 shows the rates of S/SEE, ischemic stroke, major bleeding, ICH, and mortality of patients on $2.5 \mathrm{mg}$ twice daily apixaban compared with those on $5 \mathrm{mg}$ twice daily, both in observational and in randomized studies. Regardless of study design, patients on $2.5 \mathrm{mg}$ twice daily had much higher rates of thromboembolic events, bleeding, and death than those treated with $5 \mathrm{mg}$ twice daily (1.26- to 3.16-fold). 6,7,11,14,16,18,21 Moreover, an absolute risk difference between both dosing regimens of $+1.4 \% /$ year, $+1.0 \% /$ year, $+0.3 \% /$ year, and $+9.6 \% /$ year for S/SEE, major bleeding, ICH, and all-cause death, respectively, was observed in observational studies; $;, 7,11,14,16,18$ and a $+0.4 \% /$ year for S/SEE, $+1.2 \%$ for major bleeding, and $+6.8 \% /$ year for mortality in RCTs. ${ }^{21}$ 
Table 2 Risks of thromboembolism, bleeding, and death in observational studies compared with in randomized controlled trials

\begin{tabular}{|c|c|c|c|c|c|}
\hline \multirow[b]{2}{*}{ Outcomes } & \multicolumn{2}{|c|}{ Observational studies } & \multicolumn{2}{|c|}{ Randomized controlled trials } & \multirow[b]{2}{*}{$\begin{array}{l}\text { Relative risk } \\
(95 \% \mathrm{Cl})\end{array}$} \\
\hline & $\begin{array}{l}\text { No. with events } \\
\text { (sample size) }\end{array}$ & $\% / y$ & $\begin{array}{l}\text { No. with events } \\
\text { (sample size) }\end{array}$ & $\% / y$ & \\
\hline \multicolumn{6}{|c|}{ Apixaban, either dose } \\
\hline S/SEE & $2,050(108,765)$ & 1.8 & $161(11,928)$ & $1.4^{\mathrm{b}}$ & $1.62(1.19-1.64)$ \\
\hline Ischemic stroke & $2,283(141,527)$ & 1.6 & $119(11,928)$ & 1.0 & $1.62(1.35-1.94)$ \\
\hline Major bleeding $^{a}$ & $3,843(142,955)$ & 2.6 & $233(11,896)$ & 2.0 & $1.37(1.20-1.56)$ \\
\hline $\mathrm{ICH}$ & $807(145,863)$ & $0.6^{\mathrm{b}}$ & $41(11,896)$ & $0.4^{\mathrm{b}}$ & $1.61(1.17-2.20)$ \\
\hline All-cause death & $3,037(45,263)$ & 6.6 & $419(11,928)$ & 3.5 & $1.91(1.73-2.11)$ \\
\hline \multicolumn{6}{|c|}{ Apixaban, $5 \mathrm{mg}$ twice daily } \\
\hline S/SEE & $960(61,179)$ & 1.5 & $97(8,664)$ & 1.1 & $1.40(1.14-1.73)$ \\
\hline Ischemic stroke & $727(60,118)$ & $1.6^{\mathrm{b}}$ & $83(8,692)$ & 1.0 & $1.27(1.01-1.59)$ \\
\hline Major bleeding $^{a}$ & $1,811(64,779)$ & 2.8 & $181(8,664)$ & 2.1 & $1.34(1.15-1.56)$ \\
\hline $\mathrm{ICH}$ & $277(65,581)$ & 0.4 & NR & NR & - \\
\hline All-cause death & $413(11,010)$ & $3.5^{\mathrm{b}}$ & $281(8,692)$ & 3.2 & $1.16(1.00-1.35)$ \\
\hline \multicolumn{6}{|c|}{ Apixaban, $2.5 \mathrm{mg}$ twice daily } \\
\hline S/SEE & $760(25,556)$ & 2.9 & $6(424)$ & 1.5 & $2.10(0.95-4.67)$ \\
\hline Ischemic stroke & $488(20,409)$ & 2.2 & $6(428)$ & 1.4 & $1.71(0.77-3.79)$ \\
\hline Major bleeding ${ }^{a}$ & $1,103(28,250)$ & 3.8 & $14(424)$ & 3.3 & $1.18(0.70-1.99)$ \\
\hline $\mathrm{ICH}$ & $202(29,477)$ & 0.7 & NR & NR & - \\
\hline All-cause death & $1,461(12,241)$ & $13.1^{\mathrm{b}}$ & $43(428)$ & 10.0 & $1.19(0.89-1.58)$ \\
\hline \multicolumn{6}{|c|}{ Vitamin $\mathrm{K}$ antagonists } \\
\hline S/SEE & $5,589(225,971)$ & 2.5 & $145(9,081)$ & 1.6 & $1.55(1.32-1.82)$ \\
\hline Ischemic stroke & $5,558(311,567)$ & 1.8 & $95(9,081)$ & 1.1 & $1.71(1.39-2.09)$ \\
\hline Major bleeding ${ }^{a}$ & $14,643(339,980)$ & 4.1 & $280(9,052)$ & 3.1 & $1.39(1.24-1.56)$ \\
\hline $\mathrm{ICH}$ & $3,045(354,248)$ & $0.8^{\mathrm{b}}$ & $72(9,052)$ & 0.8 & $1.08(0.86-1.36)$ \\
\hline All-cause death & $9,691(163,084)$ & 5.8 & $358(9,081)$ & 3.9 & $1.51(1.36-1.67)$ \\
\hline
\end{tabular}

Abbreviations: \%/y, number of events per 100 patient-years; $\mathrm{Cl}$, confidence interval; ICH, intracranial hemorrhage; NR, not reported; S/SEE, the composite of stroke and systemic embolism events.

${ }^{a}$ The definitions of major bleeding varied among the observational studies. For the precise definitions of major bleeding used by the individual studies, please refer to the respective articles (see - Supplementary Material S2: - Tables 13-16).

bPooled rate derived from the random effects model due to serious inconsistency (see - Supplementary Material S1: - Tables 6 and 8).

\section{Discussion}

Our results confirm other reports and show that apixabantreated patients with AF enrolled in observational studies (1) have higher rates of thromboembolic events, as well as of bleeding and death; (2) have baseline characteristics that put them at higher risk of both thromboembolic events and bleeding; and (3) are more frequently treated with the $2.5-\mathrm{mg}$ dose than those enrolled in RCTs, of which about half (57.2\%, 95\% CI: 45.9-68.2\%) is used off-label according to results of contemporaneous observational studies (-Supplementary Material S2: - Table 17, and S3: - Figs. 33 and 34, available in the online version). ${ }^{23-31}$ In addition, our results indicate that in both observational and randomized studies, patients treated with the lower dose of apixaban demonstrate a consistent pattern of higher rates of both bleeding and mortality in addition to a higher rate of thromboembolic events.

Several authors and guidance documents have advocated against the off-label use of the 2.5-mg dose, ${ }^{23,29,32-36}$ on the grounds that it is an important cause of the excess of S/SEE reported in observational studies and daily clinical practice. ${ }^{23,29,32-34}$ However, our findings provide an additional explanation and suggest that enrolment of patients with worse risk profiles in observational studies (vs. RCTs) is an important contributor to the high rates of thromboembolic events in those receiving the 2.5-mg dose of apixaban. We base our suggestion on the following observations.

First, patients receiving the $2.5-\mathrm{mg}$ dose in observational studies had the worst prognostic characteristics of all four groups analyzed (-Table $\mathbf{1}$ ). Second, not only were the rates 
Table 3 Risks of thromboembolism, bleeding, and death for patients on $2.5 \mathrm{mg}$ twice daily apixaban compared with those on $5 \mathrm{mg}$ twice daily apixaban per study design

\begin{tabular}{|c|c|c|c|c|c|}
\hline \multirow[b]{2}{*}{ Outcome } & \multicolumn{2}{|l|}{$2.5 \mathrm{mg}$ twice daily apixaban } & \multicolumn{2}{|l|}{$5 \mathrm{mg}$ twice daily apixaban } & \multirow[b]{2}{*}{ Relative risk (95\% Cl } \\
\hline & No. with events (sample size) & $\% / y$ & No. with events (sample size) & $\% / y$ & \\
\hline \multicolumn{6}{|c|}{ In observational studies } \\
\hline S/SEE & $760(25,556)$ & 2.9 & $960(61,179)$ & 1.5 & $1.90(1.73-2.08)$ \\
\hline Ischemic stroke & $488(20,409)$ & 2.2 & $727(60,118)$ & $1.6^{\mathrm{b}}$ & $1.98(1.77-2.22)$ \\
\hline Major bleeding ${ }^{a}$ & $1,103(28,250)$ & 3.8 & $1,811(64,779)$ & 2.8 & $1.40(1.30-1.50)$ \\
\hline $\mathrm{ICH}$ & $202(29,477)$ & 0.7 & $277(65,581)$ & 0.4 & $1.62(1.35-1.94)$ \\
\hline All-cause death & $1,461(12,241)$ & $13.1^{\mathrm{b}}$ & $413(11,010)$ & $3.5^{\mathrm{b}}$ & $3.16(2.84-3.51)$ \\
\hline \multicolumn{6}{|c|}{ In randomized controlled trials } \\
\hline S/SEE & $6(424)$ & 1.5 & $97(8,664)$ & 1.1 & $1.26(0.56-2.87)$ \\
\hline Ischemic stroke & $6(428)$ & 1.4 & $83(8,692)$ & 1.0 & $1.47(0.64-3.34)$ \\
\hline Major bleeding & $14(424)$ & 3.3 & $181(8,664)$ & 2.1 & $1.58(0.93-2.70)$ \\
\hline $\mathrm{ICH}$ & NR & NR & NR & NR & - \\
\hline All-cause death & $43(428)$ & 10.0 & $281(8,692)$ & 3.2 & $3.11(2.29-4.22)$ \\
\hline
\end{tabular}

Abbreviations: \%/y, number of events per 100 patient-years; $\mathrm{Cl}$, confidence interval; ICH, intracranial hemorrhage; NR, not reported; S/SEE, the composite of stroke and systemic embolism events.

${ }^{a}$ The definitions of major bleeding varied among the observational studies. For the precise definitions of major bleeding used by the individual studies, please refer to the respective articles (see - Supplementary Material S2: - Tables 13-16).

${ }^{b}$ Pooled rate derived from the random effects model due to serious inconsistency (see - Supplementary Material S1: - Tables 6 and 8).

of thromboembolic events higher but those of major bleeding and mortality were also higher in observational studies compared with RCTs, which was evident for both apixabanand VKA-treated patients (-Table 2). Moreover, the higher events rates for all three outcomes were consistently seen with both the 5- and 2.5-mg doses of apixaban (-Table 2). Finally, relative to those taking the full dose, patients treated with the lower dose not only had higher rates of thromboembolic events but also higher rates of bleeding and a strikingly greater risk of mortality that cannot be accounted for by the difference in rates of thromboembolic events. The higher bleeding rate as well as the mortality unrelated to thromboembolism cannot be attributable to underdosing and therefore to off-label use of the 2.5-mg dose (-Table 3). Thus, although the design of our study does not allow us to quantify the relative contributions of underdosing and patient-related factors, our results suggest that the inclusion of higher risk patients in observational studies is an important contributor to the increased rates of S/SEE in patients who are treated with $2.5 \mathrm{mg}$ apixaban.

Pharmacokinetic and clinical studies that established and validated the $\mathrm{ABC}$ criteria excluded many patients at high risk of bleeding who were included in the observational studies and are treated with apixaban in clinical practice. ${ }^{1,2,21,49}$ Given the differences between the populations, it is therefore unclear whether some patients seen in clinic, who are deemed to be at very high risk of bleeding or overexposure to apixaban, would be better served if they were treated with an on-label $5 \mathrm{mg}$ dose or off-label $2.5 \mathrm{mg}$ dose of apixaban. Until we have more data, physicians will have to use their clinical judgment when dosing apixaban in these patients.

\section{Strengths and Limitations}

The main strengths of our study is that we performed a systematic search for observational and randomized studies, compared the differences in baseline characteristics and rates of most important adverse outcomes for patients with AF (S/SEE, ischemic stroke, major bleeding, ICH, and mortality) between these two study designs, and by apixaban dose.

The main limitations of our study are that: (1) our conclusion is based on analyses of nonrandomized data; (2) the indirect comparisons included only two randomized studies; (3) the proportion of off-label use was not reported by individual observational studies included in our metaanalysis, and we relied on data from contemporaneous observational studies to obtain the best estimates of the prevalence of off-label use; (4) a modest number of patients were prescribed the $2.5-\mathrm{mg}$ dose of apixaban in the RCTs $(n=596)$, and of these, we were only able to derive data on clinical characteristics and event rates from 145 (a substudy of AVERROES), ${ }^{48}$ and 428 patients (ARISTOTLE), ${ }^{21}$ respectively; and (5) our design does not provide definitive information on the criteria that should be used in clinical practice to select patients for apixaban dose reduction. Only a well-designed RCT would provide the required information.

\section{Conclusion}

The higher risk profiles of patients in clinical practice compared with RCTs, and higher rates of both bleeding and mortality not attributable to thromboembolism in patients treated with apixaban $2.5 \mathrm{mg}$ twice daily compared with 
$5 \mathrm{mg}$ twice daily suggest that differences in patient characteristics are additional important contributors to the higher than expected thromboembolic event rates in clinical practice.

\section{What is known about this topic?}

- Rates of thromboembolic events in patients with atrial fibrillation prescribed apixaban are higher in observational studies than in the pivotal randomized trials.

- The 2.5-mg dose of apixaban is used much more frequently in clinical practice than in randomized trials, and approximately $50 \%$ of patients who receive this dose in clinical practice do not meet the labeled criteria for dose reduction. Recent reports associate off-label use of $2.5 \mathrm{mg}$ apixaban with higher rates of thromboembolic events.

- Accordingly, there is a prevailing view that the offlabel use of the 2.5-mg dose is an important cause of higher rates of thromboembolic events in observational studies relative to randomized studies, and consequently, that such use should be avoided in all patients.

\section{What does this paper add?}

- The higher risk profiles of patients in observational versus randomized studies, and higher rates of both bleeding and mortality not attributable to thromboembolism in patients treated with apixaban $2.5 \mathrm{mg}$ twice daily versus $5 \mathrm{mg}$ twice daily suggest that differences in patient characteristics are additional important contributors to the higher than expected thromboembolic event rates in clinical practice.

\section{Authors' Contributions}

T.A.C.V., J.H., V.C.B., J.W.E., J.S.G., P.C.K., and N.C.C. have contributed to the concept and design of the study. T.A.C. V., J.H., and N.C.C. developed the study protocol, designed, and coordinated the study. T.A.C.V., K.X., and N.C.C. developed the search strategy. T.A.C.V. and K.X. tailored the search strategy, performed the literature searches, and extracted the data. T.A.C.V. and K.X. performed the quality assessments, and any disagreement was resolved by N.C.C., T.A.C.V., J.H., V.C.B., J.S.G., J.W.E., and N.C.C. developed the initial analysis plan. T.A.C.V. and I.M. performed the analysis. T.A.C.V., J.H., and N.C.C. wrote the initial draft and subsequent iterations. All the other authors reviewed the drafts, provided critical comments, and revised the initial draft to produce the final manuscript.

\section{Conflict of Interest}

T.A.C.V. has received honoraria from Daiichi Sankyo. J.W.E. has received honoraria and research support from Astra-Zeneca, Bayer, Boehringer Ingelheim, Bristol-Myers Squibb, Daiichi Sankyo, Janssen, Pfizer, Portola, and
Sanofi. V.C.B. has received grants from Pfizer, Canada and honoraria from Bayer. N.C.C. has received honoraria from Bayer. Other authors report no conflicts of interests.

\section{Acknowledgements}

T.A.C.V. was supported by two educational scholarships: the Marco Polo Scholarship from the University of Groningen and the De Cock-Hadders scholarship from the De Cock-Hadders foundation. K.X. was supported by an educational grant from the China Scholarship Council. P.C.K. was supported by an educational grant from the Haematology Society of Australia and New Zealand. J.W.E. is the recipient of a midcareer award from the Heart and Stroke Foundation and holds the Jack Hirsh/Population Health Research Institute Chair in Thrombosis and Atherosclerosis. N.C.C. holds a McMaster University, Department of Medicine Internal Career Research Award.

\section{References}

1 Connolly SJ, Eikelboom J, Joyner C, et al; AVERROES Steering Committee and Investigators. Apixaban in patients with atrial fibrillation. N Engl J Med 2011;364(09):806-817

2 Granger CB, Alexander JH, McMurray JJ, et al; ARISTOTLE Committees and Investigators. Apixaban versus warfarin in patients with atrial fibrillation. N Engl J Med 2011;365(11):981-992

3 Adeboyeje G, Sylwestrzak G, Barron JJ, et al. Major bleeding risk during anticoagulation with warfarin, dabigatran, apixaban, or rivaroxaban in patients with nonvalvular atrial fibrillation. J Manag Care Spec Pharm 2017;23(09):968-978

4 Chan YH, Lee HF, See LC, et al. Effectiveness and safety of four direct oral anticoagulants in Asian patients with nonvalvular atrial fibrillation. Chest 2019;156(03):529-543

5 Chan YH, See LC, Tu HT, et al. Efficacy and safety of apixaban, dabigatran, rivaroxaban, and warfarin in Asians with nonvalvular atrial fibrillation. J Am Heart Assoc 2018;7(08):e008150

6 Cho MS, Yun JE, Park JJ, et al. Outcomes after use of standard- and low-dose non-vitamin $\mathrm{K}$ oral anticoagulants in Asian patients with atrial fibrillation. Stroke 2018. Strokeaha118023093

7 Ellis MH, Avnery P, Derazne E, et al. Bleeding in patients with atrial fibrillation treated with different doses of direct oral anticoagulants and vitamin $\mathrm{k}$ antagonists: a population-based study. Blood 2016;128(22):2617

8 Halvorsen S, Ghanima W, Fride Tvete I, et al. A nationwide registry study to compare bleeding rates in patients with atrial fibrillation being prescribed oral anticoagulants. Eur Heart J Cardiovasc Pharmacother 2017;3(01):28-36

9 Hohnloser SH, Basic E, Hohmann C, Nabauer M. Effectiveness and safety of non-vitamin $\mathrm{k}$ oral anticoagulants in comparison to phenprocoumon: data from 61,000 patients with atrial fibrillation. Thromb Haemost 2018;118(03):526-538

10 Inoue H, Umeyama M, Yamada T, Hashimoto H, Komoto A, Yasaka M. Safety and effectiveness of apixaban in Japanese patients with nonvalvular atrial fibrillation in clinical practice: a regulatory postmarketing surveillance, the STANDARD study. J Arrhythm 2019;35(03):506-514

11 Inoue H, Umeyama M, Yamada T, Hashimoto H, Komoto A, Yasaka M. Safety and effectiveness of reduced-dose apixaban in Japanese patients with nonvalvular atrial fibrillation in clinical practice: a sub-analysis of the STANDARD study.J Cardiol 2020;75(02):208-215

12 Kjerpeseth LJ, Selmer R, Ariansen I, Karlstad Ø, Ellekjær H, Skovlund E. Comparative effectiveness of warfarin, dabigatran, rivaroxaban and apixaban in non-valvular atrial fibrillation: a nationwide pharmacoepidemiological study. PLoS One 2019;14 (08): $\mathrm{e} 0221500$ 
13 Lamberts M, Staerk L, Olesen JB, et al. Major bleeding complications and persistence with oral anticoagulation in non-valvular atrial fibrillation: contemporary findings in real-life Danish patients. J Am Heart Assoc 2017;6(02):e004517

14 Larsen TB, Skjøth F, Nielsen PB, Kjældgaard JN, Lip GY. Comparative effectiveness and safety of non-vitamin $\mathrm{K}$ antagonist oral anticoagulants and warfarin in patients with atrial fibrillation: propensity weighted nationwide cohort study. BMJ 2016;353:i3189

15 Lee SR, Choi EK, Kwon S, et al. Effectiveness and safety of contemporary oral anticoagulants among Asians with nonvalvular atrial fibrillation. Stroke 2019;50(08):2245-2249

16 Lip GYH, Keshishian A, Li X, et al. Effectiveness and safety of oral anticoagulants among nonvalvular atrial fibrillation patients. Stroke 2018;49(12):2933-2944

17 Mueller T, Alvarez-Madrazo S, Robertson C, Wu O, Bennie M. Comparative safety and effectiveness of direct oral anticoagulants in patients with atrial fibrillation in clinical practice in Scotland. Br J Clin Pharmacol 2019;85(02):422-431

18 Nielsen PB, Skjøth F, Søgaard M, Kjældgaard JN, Lip GY, Larsen TB. Effectiveness and safety of reduced dose non-vitamin $\mathrm{K}$ antagonist oral anticoagulants and warfarin in patients with atrial fibrillation: propensity weighted nationwide cohort study. BMJ 2017;356:j510

19 Ramagopalan SV, Sicras-Mainar A, Polanco-Sanchez C, Carroll R, de Bobadilla JF. Patient characteristics and stroke and bleeding events in nonvalvular atrial fibrillation patients treated with apixaban and vitamin K antagonists: a Spanish real-world study. J Comp Eff Res 2019;8(14):1201-1212

20 Vinogradova Y, Coupland C, Hill T, Hippisley-Cox J. Risks and benefits of direct oral anticoagulants versus warfarin in a real world setting: cohort study in primary care. BMJ 2018;362:k2505

21 Rose M, Beasley BN. Center for drug evaluation and research application number: 202155orig1s000 medical review(s). Published 2012. Updated December 17, 2012. Available at: https:// www.accessdata.fda.gov/drugsatfda_docs/nda/ 2012/2021550rig1s000MedR.pdf. Accessed December 18, 2019

22 Rivera-Caravaca JM, Esteve-Pastor MA, Marín F, et al. A propensity score matched comparison of clinical outcomes in atrial fibrillation patients taking vitamin k antagonists: comparing the "realworld" vs clinical trials. Mayo Clin Proc 2018;93(08):1065-1073

23 Santos J, Antonio N, Rocha M, Fortuna A. Impact of direct oral anticoagulants off-label doses on clinical outcomes of atrial fibrillation patients: a systematic review. Br J Clin Pharmacol 2020;86(03):533-547

24 Barra ME, Fanikos J, Connors JM, Sylvester KW, Piazza G, Goldhaber SZ. Evaluation of dose-reduced direct oral anticoagulant therapy. Am J Med 2016;129(11):1198-1204

25 Başaran Ö, Dogan V, Beton O, et al; Collaborators. Suboptimal use of non-vitamin K antagonist oral anticoagulants: results from the RAMSES study. Medicine (Baltimore) 2016;95(35):e4672

26 Gibson CM, Smith CB, Davis S, Scalese MJ. Assessment of apixaban prescribing patterns for nonvalvular atrial fibrillation in hospitalized patients. Ann Pharmacother 2018;52(01):54-59

27 Okumura Y, Yokoyama K, Matsumoto N, et al; The Sakura Af Registry Investigators. Current use of direct oral anticoagulants for atrial fibrillation in Japan: findings from the SAKURA AF Registry. J Arrhythm 2017;33(04):289-296

28 Schafer JH, Casey AL, Dupre KA, Staubes BA. Safety and efficacy of apixaban versus warfarin in patients with advanced chronic kidney disease. Ann Pharmacother 2018;52(11):1078-1084

29 Steinberg BA, Shrader P, Thomas L, et al; ORBIT-AF Investigators and Patients. Off-label dosing of non-vitamin $\mathrm{k}$ antagonist oral anticoagulants and adverse outcomes: the Orbit-AF II Registry. J Am Coll Cardiol 2016;68(24):2597-2604
30 Umei M, Kishi M, Sato T, et al. Indications for suboptimal low-dose direct oral anticoagulants for non-valvular atrial fibrillation patients. J Arrhythm 2017;33(05):475-482

31 Yamashita Y, Uozumi R, Hamatani Y, et al. Current status and outcomes of direct oral anticoagulant use in real-world atrial fibrillation patients- Fushimi AF Registry. Circ J 2017;81(09): 1278-1285

32 Arbel R, Sergienko R, Hammerman A, et al. Effectiveness and safety of off-label dose-reduced direct oral anticoagulants in atrial fibrillation. Am J Med 2019;132(07):847-855.e3

33 Steinberg BA, Shrader P, Pieper K, et al; Outcomes Registry for Better Informed Treatment of Atrial Fibrillation (ORBIT-AF) II Investigators. Frequency and outcomes of reduced dose nonvitamin $\mathrm{k}$ antagonist anticoagulants: results from Orbit-AF II (the Outcomes Registry for Better Informed Treatment of Atrial Fibrillation II). J Am Heart Assoc 2018;7(04):e007633

34 Yao X, Shah ND, Sangaralingham LR, Gersh BJ, Noseworthy PA. Non-vitamin $\mathrm{k}$ antagonist oral anticoagulant dosing in patients with atrial fibrillation and renal dysfunction. J Am Coll Cardiol 2017;69(23):2779-2790

35 Kirchhof P, Benussi S, Kotecha D, et al; ESC Scientific Document Group. 2016 ESC Guidelines for the management of atrial fibrillation developed in collaboration with EACTS. Eur Heart J 2016;37 (38):2893-2962

36 Steffel J, Verhamme P, Potpara TS, et al; ESC Scientific Document Group. The 2018 European Heart Rhythm Association Practical Guide on the use of non-vitamin K antagonist oral anticoagulants in patients with atrial fibrillation. Eur Heart J 2018;39(16): 1330-1393

37 Spencer FA, Iorio A, You J, et al. Uncertainties in baseline risk estimates and confidence in treatment effects. BMJ 2012;345: e7401-e7401

38 Iorio A, Spencer FA, Falavigna M, et al. Use of GRADE for assessment of evidence about prognosis: rating confidence in estimates of event rates in broad categories of patients. BMJ 2015;350:h870

39 Cohen J. Statistical Power Analysis for the Behavioral Sciences. New York: Routledge; 1988. Doi: 10.4324/9780203771587

40 Borenstein M, Hedges LV, Higgins JPT, Rothstein HR. Introduction to Meta-Analysis. Chichester, UK: Wiley; 2009

41 DerSimonian R, Laird N. Meta-analysis in clinical trials. Control Clin Trials 1986;7(03):177-188

42 Freeman M, Tukey J. Transformations related to the angular and the square root. Ann Math Stat 1950;21:607-611

43 Wan X, Wang W, Liu J, Tong T. Estimating the sample mean and standard deviation from the sample size, median, range and/or interquartile range. BMC Med Res Methodol 2014;14:135

44 Altman DG. Practical Statistics for Medical Research. London: Chapman and Hall; 1991

45 Altman DG. Confidence intervals for the number needed to treat. BMJ 1998;317(7168):1309-1312

46 Daly LE. Confidence limits made easy: interval estimation using a substitution method. Am J Epidemiol 1998;147(08):783-790

47 Lopes RD, Al-Khatib SM, Wallentin L, et al. Efficacy and safety of apixaban compared with warfarin according to patient risk of stroke and of bleeding in atrial fibrillation: a secondary analysis of a randomised controlled trial. Lancet 2012;380(9855):1749-1758

48 Bhagirath VC, Eikelboom JW, Hirsh J, et al. Apixaban-calibrated anti-FXa activity in relation to outcome events and clinical characteristics in patients with atrial fibrillation: results from the AVERROES trial. TH Open 2017;1(02):e139-e145

49 Paikin JS, Hirsh J, Chan NC, Ginsberg JS, Weitz JI, Eikelboom JW. Timing the first postoperative dose of anticoagulants: lessons learned from clinical trials. Chest 2015;148(03):587-595 